\title{
THE ART OF THE DELPHI TECHNIQUE: HIGHLIGHTING ITS SCIENTIFIC MERIT
}

\author{
Dr Emmerentia du Plessis \\ PhD (Nursing Science) \\ Senior Lecturer, School of Nursing Science, North-West University, Potchefstroom campus \\ Corresponding author: Emmerentia.DuPlessis@nwu.ac.za
}

\author{
Prof Susara P Human \\ D Cur (Community Health) \\ Associate Professor, Department of Health Studies, University of South Africa, Pretoria
}

Keywords: Delphi technique; scientific merit; process, application

\begin{abstract}
The initial use of the Delphi technique was forecasting in order to be able to plan ahead. More recently the Delphi technique has been used as a constructive method in facilitating controlled, rationale group communication to develop knowledge for decision-making. Although the Delphi technique is widely used, its scientific merit is questioned. This article illuminates the application, limitations, value and scientific merit of the Delphi technique. The subsequent articles illustrate the application of the Delphi technique.
\end{abstract}

\section{OPSOMMING}

Die aanvanklike toepassing van die Delphi-tegniek was voorspelling met die doel om vooruit te kan beplan. Meer onlangs word die Delphi-tegniek gebruik as 'n konstruktiewe metode om gekontrolleerde, rasionele groepkommunikasie te fasiliteer om kennis vir besluitneming te ontwikkel. Alhoewel die Delphi-tegniek wyd toegepas word, word die wetenskaplikheid daarvan bevraagteken. Die artikel lig die toepassing, beperkinge, waarde en wetenskaplikheid van die Delphi-tegniek uit. Die volgende artikels sal die toepassing van die Delphi-tegniek illustreer. 


\section{INTRODUCTION}

This article on the Delphi technique forms part of a series of three articles based on research entitled: A strategy to promote nurses' health research contribution in South Africa (Du Plessis, 2007). The subsequent article describes the application of the Delphi technique, while a follow-up research phase to further explore the results of the Delphi study is presented as the third article.

The need for the article on the Delphi technique crystallised during the planning phase of the research, when an in-depth view of the Delphi study was required, to explore the scientific merit of this technique, as well as to ensure adequate planning of the research. Relevant literature on this technique as well as on the application of this technique were searched by means of a literature search on the Ebscohost database, including the following databases: Academic search premier, CINAHL, ERIC, MEDLINE, PsychINFO, and Health source: Nursing/Academic edition.

\section{THE DELPHI TECHNIQUE}

The Delphi technique lends its name from Greek mythology, from the ancient story of the oracle of Delphi. This was a holy place where the master of Delphi, Apollo, known for his ability to forecast the future, was consulted (Goodman, 1987:729; Powell Kennedy, 2004:505). The initial use of the Delphi technique was indeed forecasting in order to plan ahead.

The Delphi technique was developed by the Rand Corporation in the period of the late 1940s to the early 1970s, as a novel tool used in "Project Delphi" to estimate the probable effects of a massive atomic bomb attack on the United States of America to enable effective decision-making by the defence force of the day (Helmer, 1975:xix; Sackman, 1974:iii; Linstone \& Turoff, 1975:10). These early developments were headed by two scientists, Olaf Helmer and Norman Dalkey, who strove to develop the Delphi technique as a scientifically sound research technique, although Helmer (1975:xix) acknowledged that at that time, the Delphi technique was "more of an art than a science". They therefore repeatedly conducted research to prove that the Delphi technique produced valid research results. In one of these studies, Dalkey and Rourke (1971:iii) in fact found that the Delphi technique was not only useful to elicit and effectively reflect opinions based on factual estimates, as in the original study, but also opinions based on intuition and judgement. At that time, Fusfeld (1971:4) agreed that Delphi research elicited sound scientific evidence, and added that the Delphi technique has proven that the statistical summary of individuals' opinions "are more accurate than predictors derived from group interaction or single individuals". Sackman (1974:iii), however, later heavily criticised the scientific merit of this technique, recommending against its further use by the Rand Corporation until it's scientific merit could be proven.

In spite of this criticism, the Delphi technique continued to be implemented by a number of disciplines, including health sciences. The definition of and rationale for using this technique and the characteristics of the Delphi technique will be discussed. Thereafter the process followed in the Delphi technique will be explained. This technique's scientific merit is focussed on as part of this discussion. The subsequent article, entitled: "Opinions on a strategy to promote nurses' health research contribution in South Africa" serves as an example of a study in which the Delphi technique was used.

\section{DEFINITION OF THE DELPHI TECHNIQUE}

From the above information it seems that the Delphi technique was initially developed as a very specific tool in specific circumstances, and was later developed as a research tool for a wider scope of application. For example, one of the objectives of the original study was to "obtain the most reliable consensus of opinion of a group of experts by a series of intensive questionnaires interspersed with controlled opinion feedback" (Linstone \& Turoff, 1975:10).

One could argue that if the above statement is seen as a definition of the Delphi technique, it might be lacking in comprehensiveness and the ability to act as universal guideline. Interestingly, it seems that a pattern in literature exists that authors, such as Powell (2003:376), refer to this statement as the definition of the Delphi technique, as well as that researchers and authors generally use narrow definitions to describe the Delphi technique. De Villiers, De Villiers and Kent (2005:1) refer to the Delphi technique as a series of 
questionnaires to generate expert opinion in an anonymous fashion which takes place over a series of rounds. Burns and Grove (2005:407) define it as a method to measure the judgements of a group of experts, for the purpose of making decisions, assessing priorities or making forecasts. Brink (2002:208) focuses on the aspect of consensus, by indicating that the technique is a data collection method that uses several rounds of questions to seek a consensus on a particular topic from a group of experts on the topic.

Indeed, Linstone and Turoff (1975:3) acknowledged the difficulty in providing an exact definition of the Delphi technique because of its adaptable nature, but attempted to, in broad terms, define the Delphi technique as "a method for structuring a group communication process so that the process is effective in allowing a group of individuals, as a whole, to deal with a complex problem".

This definition provides a broader perspective on the Delphi technique and describes its core, namely that a group communication process is involved and that there is a need for decision-making to deal with a specific issue.

\section{RATIONALE BEHIND USING THE DELPHI TECHNIQUE}

Cook, Brismeé and Sizer (2005:6) as well as Powell (2003:376) indicate that the Delphi technique is used in situations where vague, unknown or contradictory opinions exist, while limited scientific evidence to guide evidence-based decision-making exists. Linstone and Turoff (1975:11) indicated that this technique is specifically valuable when groups of experts are geographically dispersed. Additionally, the Delphi technique is used in situations where group bias and group dynamics, such as power and group pressure, might play a role in forcing individual group members to conform to group opinion (Ganssle, 2004:2; Garavalia \& Gredler, 2004:376-377). The use of the Delphi technique reduces the influence these factors might have (Deshpande, Shiffman \& Nadkarni, 2005:50). This technique thus has value in the health care sector which is characterised by multi-disciplinary teams and hierarchical structures (Beech, 1999:284).

Hasson, Keeney and McKenna (2000:1009), however, warn that the decision to use the Delphi technique requires careful consideration of various factors, for example the researchers' competence as well as resources and logistical considerations. Powell (2003:377) agrees and states that the technique should only be used if it is the opinion of the researcher that the use of the technique can provide more accurate data than methods obtaining data from either individuals or interacting groups. Most importantly, the research problem should guide the decision on a research method, and alternative research methods should be considered to ensure that the most appropriate research method is used (Powell, 2003:377).

Linstone and Turoff (1975:11) insightfully indicated that "problems linked to group communication and decisions that lend themselves to the use of group involvement" are appropriate to explore by means of the Delphi technique. Furthermore, Hasson et al. (2000:1009) as well as McKenna (1994:1222) refer to research objectives, as identified by Linstone and Turoff, which indicate the appropriate use of this technique, namely:

- $\quad$ "To explore or expose underlying assumptions or information leading to differing judgements;

- To seek out information which may generate a consensus on the part of the respondent group;

- $\quad$ To correlate informed judgements on a topic spanning a wide range of disciplines;

- $\quad$ To educate the respondent group as to the diverse and interrelated aspects of the topic".

The following are examples of research problems or research objectives that were explored by means of the Delphi technique in recent research:

- Almasio, Niero, Angioli, Ascione, Minoli, Oprandi, Pinzello, Verme and Andriulli (2005:382) identified a research problem that the usefulness of liver biopsy in chronic viral hepatitis was not clear and experts' insight on this matter varied considerably.

- One of the objectives of research conducted by Avery, Savelyich, Sheikh, Gantrill, Morris, Fernando, Bainbridge, Horsfield and Teasdale (2005:4) was to identify and reach consensus on key clinical scenarios involving patient safety for which general practitioners might benefit from information technology support, particularly in relation to medicines management.

- Carrol (2004:33) identified the problem that no study has yet elucidated the core clinical skills that nurses 
working in medical assessment units should possess.

- Research conducted by Cohen, Harle, Woll, Despa and Munsell (2004:1011) enabled oncology nurses to identify research priorities as a starting point in the development of a clinical nursing research programme at a large comprehensive cancer centre.

- Cook et al. (2005:59) identified the research problem that clinical spine instability is poorly defined and difficult to diagnose.

- French, Anderson, Burnard, Holmes, Mashaba, Wong and Bingh-Hua (1996:595) identified the need that "curricula in different countries were different and that there was room for exploration into areas of commonality and difference", especially in the view of the need that student nurses has to develop a global perspective.

- Du Plessis (2007:213-238) gathered the opinions of stakeholders in research on nurses' research contribution in South Africa.

\section{CHARACTERISTICS OF THE DELPHI TECHNIQUE}

To further clarify the uniqueness and appropriate use of the Delphi technique, the distinguishing characteristics of the technique is discussed.

Different authors (Almasio et al. 2005:382; Armstrong, Parsons \& Barker, 2000:298; Beech, 1999:285; Deshpande et al. 2005:50; Powell, 2003:377; McKenna, 1994:1222; Goodman, 1987:730) describe core characteristics of the Delphi technique. These characteristics can be summarised as anonymity, iteration and controlled feedback, statistical group response and the use of experts as participants, as discussed below. These characteristics distinguish the Delphi technique from other group data collection methods, and therefore it could also be referred to as the essential requirements of the Delphi technique.

\section{Anonymity}

Anonymity is employed to create the advantage that participants freely and honestly express their opinions, without the inhibiting factors of peer group pressure and group bias. Anonymity is achieved by asking participants, who do not meet each other face to face, to anonymously and individually complete questionnaires.
The risk exists that the anonymity of participants and their responses might lead to a lack of accountability in responses. This could be counteracted by careful selection of participants, as well as by asking participants to justify their responses.

Another important aspect to keep in mind is that the person coordinating the research should have access to some identifying information in order to return results of a previous round to participants for further consideration. True anonymity is therefore not always possible, and the argument is that one should rather refer to quasi-anonymity. To enhance anonymity identifying information should be separated from responses, and responses should be given a code, before data analysis takes place.

\section{Iteration and controlled feedback}

The Delphi technique employs repeated rounds of data collection and analysis until a specific group opinion or judgement becomes evident. The aim of this process is to facilitate or discover an opinion representative of the specific group of participants.

\section{Statistical group response}

During the execution of the sequential rounds, participants' opinions or judgements are communicated to them by means of a statistical summary of the group's view. This enables participants to re-evaluate their own opinion in light of the group's opinion.

\section{Selection of experts as respondents}

The Delphi technique is also characterised by the use of a panel of experts as participants in order to obtain a knowledgeable opinion. There seems to be ambiguity regarding the term "expert" as used in relation to the Delphi technique. It is argued that there are no universal measures to identify these "experts". For some issues no formal definition of "expert" exists, for example quality of life issues. The requirement of at least being an informed advocate is then used to identify participants. Researchers using the Delphi technique should clearly define the concept "experts" as used in their research. 


\section{RESEARCH PROCESS}

The research process used in the Delphi technique is subsequently discussed by referring to the researcher or team of researchers, tasks in the research process, the nature of the process, sampling, data gathering, data analysis and consensus.

\section{Researcher or team of researchers}

The process is carried out by either an individual researcher, as described for example, by Garavalia and Gredler (2004:376), or by a research team (Almasio et al. 2005:382; Cohen et al. 2004:1012). From this literature, the general conclusion can be drawn that conducting research in a team enhances the execution of research. For example, it seems valuable to include, besides researchers in the field of study, managers and opinion makers as well as biostatisticians and/or health science communication experts in the research team to enhance the quality and utilisation of the research. Interestingly, in the study by French et al. (1996:596) the panel of experts from whom opinions were gathered was also the research team. This raises questions about the objectivity of this research.

\section{Tasks in the research process}

The tasks of the researcher or research team using the Delphi technique mirror the tasks of the general research process, but authors specifically mention the following:

- identifying a problem (Avery et al. 2005:5);

- designing a strategy for the Delphi study (Almasio et al. 2005:382);

- developing a broad question (Avery et al. 2005:5) or questionnaire (Garavalia \& Gredler, 2004:376);

- selection of participants (Almasio et al. 2005:382); and

- conducting and coordinating the process involved in the Delphi technique (Cohen et al. 2004:1012; Garavalia \& Gredler, 2004:376).

Pilot testing should also be included in this list of tasks, as Powell (2003:378) indicates that pilot testing is optional but preferable in the Delphi technique, and Hasson et al. (2000:1010) indicate that pilot testing should precede the implementation of the technique.

\section{The nature of the process}

The process followed in the Delphi technique is systematic (Beech, 1999:283) and has a repetitive nature (Evans, Rogers, McGraw, Battle \& Furniss, 2004:52). Authors agree that it is a multistage process (Hasson et al. 2000:1008) with multiple, successive rounds (Beech, 1999:283; Deshpande et al. 2005:49; Garavalia \& Gredler, 2000:1016). Each stage forms the basis for the next stage (McKenna, 1994:1221) in that it is a repetitive process of response-analysis-feedback-response (Carrol, 2004:34-35). The process is repeated until the views or opinions of participants converge to reach group consensus or until no further substantial change in these opinions can be elicited (Deshpande et al. 2005:49, Evans et al. 2004:53). The number of rounds, usually two or three, is also guided by the time available, cost and participation fatigue (Powell, 2003:378; Hasson et al. 2000:1010).

During the research process, specific attention should be given to clearly describing decisions on the number of rounds and the selection and recruitment of experts as well as the stability of opinions between rounds (Greatorex \& Dexter, 2000:1016).

Figure 1 was adopted from Couper (as quoted by Burns \& Grove, 2005:408) and provides an illustration of the systematic, iterative process followed in the Delphi technique.

\section{Sampling}

It seems that sampling in the Delphi technique has been a topic for debate, as evident from the following discussion. However, broad guidelines regarding the composition of the sample, the sampling technique, recruitment, sample size and representativeness could be identified, and are discussed.

\section{Composition of the sample}

The composition of the sample, usually a panel of experts, varies according to the aim of the research. An example is that when the aim of the research is related to forecasting, a more homogenous group should be selected. In a research project to identify, for example, policy issues, all options available need to be identified and the use of a more diverse group might be more appropriate. 


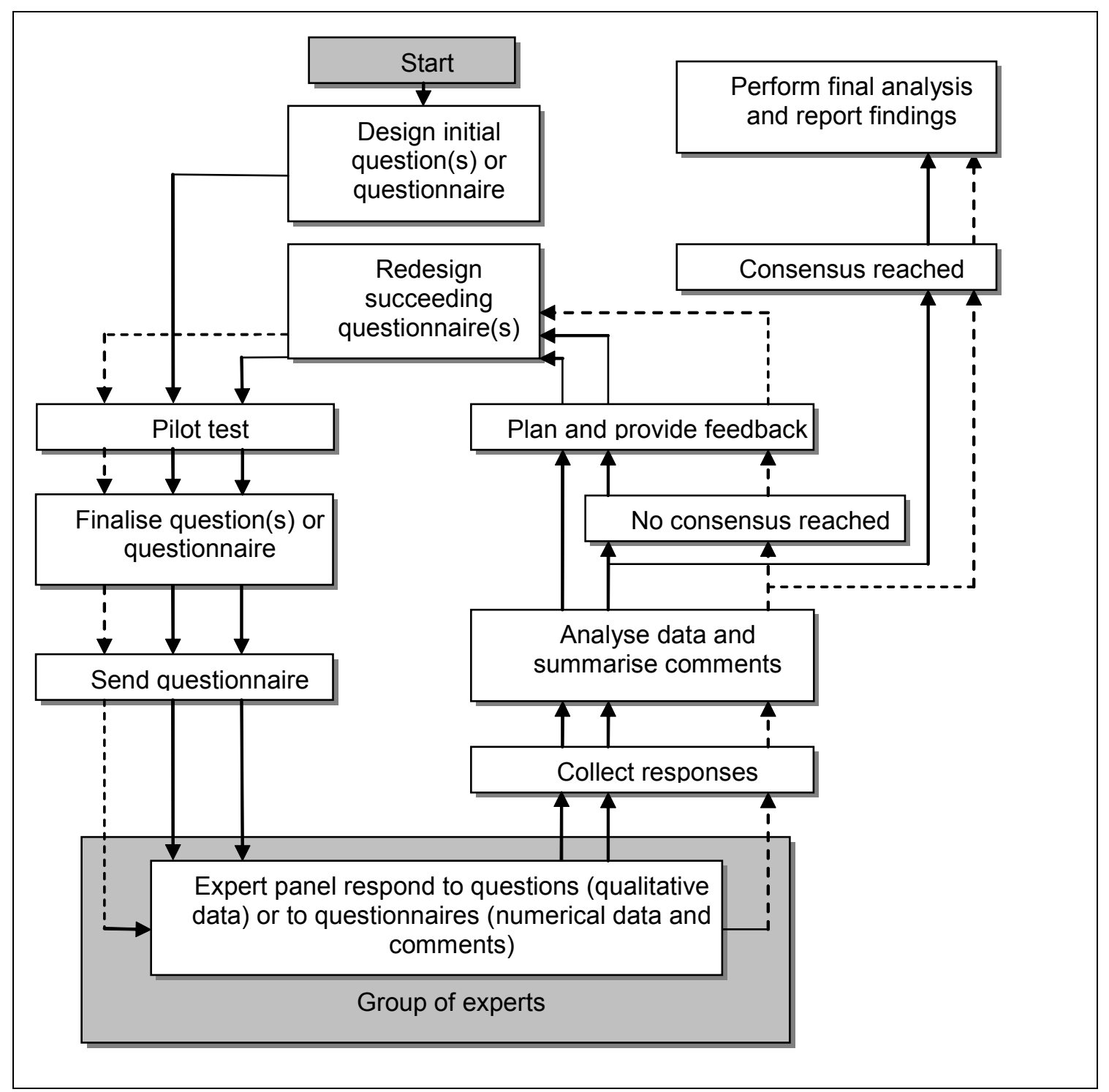

Figure 1: The nature of the process followed in the Delphi technique *

${ }^{*}$ Multiple arrows indicate repeated rounds

\section{Sampling technique}

The Delphi technique often makes use of non-random sampling techniques rather than using a random sample of panellists representing the target population (Hasson et al. 2000:1010), although there are some cases where random techniques are used. In research done by Evans et al. (2004:54), for example, stratified random sampling were used to ensure a balanced representation of different professional groups.

The non-random sampling approaches used in the Delphi technique include purposive and convenience sampling. In research done by French et al. (1996:596) the principal investigator used convenience sampling to identify institutions in different countries to be included in the study, and then requested the selected institutions to identify possible participants.
Purposive sampling is mostly used, and participants are identified based on selection criteria. These selection criteria are mostly inclusion criteria. Armstrong et al. (2000:298), for example, defined expertise according to criteria applicable to their study, and then selected nurses complying to this definition, working in a specific setting, who were willing to participate. Exclusion criteria are also used, for example in a study by Almasio et al. (2005:382).

Participants should be selected to ensure an adequate scope of expertise and views on the topic, and they should be available to participate within a certain timeframe (Avery et al. 2005:4). Powell (2003:379) adds that potential participants should be willing and able to make a valid contribution, should represent a diversity of viewpoints, should be able to reflect current knowl- 
edge and be relatively impartial to the topic being investigated. Hasson et al. (2000:1010) also mention these guidelines, but contrastingly mention that participants should be interested in the research topic. Du Plessis (2007:220) found that interest in the topic is indeed important, as it contributes to an increased response rate.

A further important aspect - which might be overlooked by researchers - is that researchers should carefully consider potential participants' written communication skills and computer literacy, as the Delphi technique requires completion of questionnaires, increasingly in electronic format (Hasson et al. 2000:1010).

Another key aspect in the Delphi technique is that the qualities of the panel of experts participating in the research have to be described fully so that their credibility as experts on the specific topic can be evaluated (Powell Kennedy, 2004:505).

\section{Recruitment}

After selection criteria have been developed a database of experts is compiled (Avery et al. 2005:4; Carrol, 2004:35). Using existing databases for example, nurses listed on practitioner associations' databases poses the problem that not all participants who meet the selection criteria are selected, as these databases might be outdated (Hasson et al. 2000:1010). This problem was also encountered in the research project discussed in the subsequent article.

After developing or accessing the database, the next step is to gain access to potential participants and to recruit them for participation. This is a difficult process and requires effort, as continuous commitment from participants to participate in all rounds has to be obtained (Hasson et al. 2000:1010). A limitation of the Delphi technique is the fact that Delphi studies are characterised by low response rates, especially in the later rounds, as mentioned by Beech (1999:283), Greatorex and Dexter (2000:1022) as well as Evans et al. (2004:57). Several reasons for the low response rate might exist, and Greatorex and Dexter (2000:1022) mention a few, namely minority opinions not being taken into consideration, low motivation, disagreement with the design and content of the study, lack of faith in the initial results of the study and other reasons, such as illness.
Building a research relationship with participants (Hasson et al. 2000:1010) is therefore important. An essential starting point is recruitment letters with detailed information about the research project and what participation entails (Armstrong et al. 2000:298). Almasio et al. (2005:382) refer to this as an information package, which was, in their case, sent by e-mail. This information package might also include a note indicating that completing the questionnaire implies consent to participate, as in the case of Cohen et al. (2004:1011) who argued that, to ensure anonymity, a separate consent form didn't have to be completed. Hasson et al. (2000:1010) suggest that face-to-face interviews with potential participants to invite and inform them might be beneficial in recruiting participants, but that it should be kept in mind that this personal contact might have an influence on the research results. It should also be kept in mind that response rates might increase if potential participants, who are to be affected by the outcome of the research, are invited to participate (Hasson et al. 2000:1010).

Another suggestion is that gatekeepers could be used to recruit participants and/or to distribute questionnaires (Armstrong et al. 2000:298; Almasio et al. 2005:382) as this enhances anonymity and willingness to participate. Reminder letters or phone calls might also be implemented to enhance the response rate (Carrol, 2004:35; Hasson et al. 2000:1011).

\section{Sample size}

There is no recommended sample size in the Delphi technique (Armstrong et al. 2000:299). The sample size varies according to the scope of the problem and resources, for example, time and money (Powell, 2003:378), as well as according to the amount of data needed (Hasson et al. 2000:1010). For example Armstrong et al. (2000:299) subjectively decided on a sample size "appearing" to be sufficient to elicit a variety of opinions, and large enough to accommodate possible drop-out. A total study population could also be used, as in research conducted by Garavalia and Gredler (2004:375) (39 participants) and Cohen et al. (2004:1011) (a population of 1500 nurses).

Although there is wide variation in the sample size, Powell (2003:378) indicates that the more participants the better, as this increases the number of panel members giving their opinions and therefore increases the 
reliability of the collective group opinion.

\section{Representativeness}

The Delphi technique does not require the sample size to be statistically representative of the study population. Representativeness is assessed on the qualities of the expert panel rather than on the sample size (Powell, 2003:378). A specific consideration in the Delphi technique is that when the response rate declines in subsequent rounds, the representativeness of subgroups of participants in relation to the initial group of participants should be considered, as described by Almasio et al. (2005:384).

\section{Data gathering}

Verbs used to describe data gathering by means of the Delphi technique include exploring (Almasio et al. 2005:382), gathering, aggregating (Beech, 1999:283), eliciting, identifying (Cohen et al. 2004:1011), assessing (Deshpande et al. 2005:49), collecting (De Villiers et al. 2005:1), harnessing (Powell, 2003:376), obtaining (Linstone \& Turoff, 1975:10), posing a question to (Carroll, 2004:35) and bringing together (Ganssle, 2004:2). These verbs imply that the Delphi technique is a survey research method, as confirmed by Cohen et al. (2004:1011) and Goodman (1987:729).

The specific data that are gathered are referred to as expert opinions, views, judgement, informed judgement and/or estimates, as used by, for example, Almasio et al. (2005:382), Deshpande et al. (2005:49) and Ganssle (2004:2).

\section{Data gathering process}

The data gathering process is executed in a series of rounds, as illustrated in Diagram 1. Powell (2003:377), as well as Williams and Webb (1994:182), reports that this process of successive rounds enables systematic control in a research project, and enhances the objectivity and validity of the results obtained. Several authors, for example Powell (2003:378), Greatorex and Dexter (2000:1023), Hasson et al. (2000:1010-1012), Beech (1999:283) and Deshpande et al. (2005:49) describe this process. Drawing on these descriptions, the rounds can be explained as follows:

Many variations of the Delphi technique exist. In the classic Delphi technique the initial round of the pro- cess usually is less structured and serves as an exploratory round to obtain a broad range of views. Qualitative data are thus generated. Data are gathered either by means of a written questionnaire with openended questions, or by means of alternative measures, such as focus groups or individual interviews. These questionnaires and alternative measures enable the collection of rich and large amounts of data. Researchers may opt to limit the amount of data by means of measures such as requesting participants to limit the number of opinions given. Data obtained serve as basis for further rounds.

Semi-structured questionnaires or structured questionnaires can also be used in the first round. These questionnaires might be developed based on literature, or by listing items identified as important by the research team, or existing questionnaires might be used if applicable. Such questionnaires thus provide participants with pre-existing information, and ranking already takes place in round one. This is known as a revised or modified Delphi technique, and is criticised as those questionnaires might tend to be biased and may limit available options.

In subsequent round/s of the classic Delphi study data generated in round one are analysed, usually by means of qualitative measures, and a list of items is produced. This list of items is communicated to participants, serving as feedback to participants, as well as a stepping stone to the next round, as participants are asked to indicate their agreement or disagreement, or to rank the list of items according to an ordinal scale.

Data generated in the second round are thus quantitative in nature, and are analysed accordingly. Based on this analysis, a third questionnaire is developed, indicating the central tendency and dispersion, usually organised in rank order, of the list of items. This questionnaire is communicated to participants, in order to indicate items that have gained collective opinion. They are asked to reconsider items in light of their initial opinions and to comment. Comments could be included in the analysis of data, providing a fuller indication of all items. This round serves to refine the results from the previous rounds. The successive rounds of feedback tend to facilitate convergence of group opinion.

Researchers need to explain and thoroughly describe 
this process in research reports, in order to demonstrate the reliability and validity of the research. Also, criticism relating to the use of questionnaires raises questions about the accurate interpretation of results, as uncertainties about questions and meanings attached can not be further explored or explained by the researcher. Careful consideration should thus be given to the development of the questionnaires.

\section{Data analysis}

Data produced in the initial round are usually qualitative of nature, and content analysis is typically used to analyse data (Powell, 2003:379; Hasson et al. 2000:1012). Analysis entails grouping similar themes together (Beech, 1999:285) to produce a list of items. The results of this analysis need to be verified to ensure a fair representation of the data generated in round one (Hasson et al. 2000:1012). Armstrong et al. (2000:297) for example, requested an additional, independent researcher to verify the analysis of data in order to promote the validity of items generated.

The list of items should be structured in order to produce a questionnaire to use in the following round. Hasson et al. (2000:1012) suggest that an informal literature review and meta-analysis might be conducted to aid the development of the questionnaire. Further important aspects regarding the development of the subsequent questionnaire are that the wording used by participants in the first round should, as far as possible, not be changed and that the researcher should not add items other than produced in the first round (Hasson et al. 2000:1010). Infrequently occurring items should be included in the subsequent questionnaire, based on the principle that participants should decide on the importance of items, not the researcher (Hasson et al. 2000:1010). Additionally, the list of items could be reduced by including only those items that achieved a certain scoring (French et al. 1996:596-7). However, the full list of items should be reflected in the research report.

In subsequent rounds, descriptive (Evans et al. 2004:55; Cohen et al. 2004:1012; Greatorex \& Dexter, 2000:1023) as well as inferential (Hasson et al. 2000:1012) statistics are used to summarise data. These statistical summaries are produced for each item and are used to determine the level of collective opinion (Hasson et al. 2000:1012). Central tendencies (mean, median, mode) as well as levels of dispersion (standard deviation, inter-quartile range) are of importance (Hasson et al. 2000:1012). Greatorex and Dexter (2000:1016) explain that if the scale according to which participants evaluated items is interval, the mean (as an indication of central tendency) represents group opinion and the standard deviation (as measure of spread) represents the amount of disagreement. A decision should be made regarding an acceptable value of the mean or standard deviation to indicate consensus. According to Greatorex and Dexter (2000:1023) this decision is taken by the researcher and defining such values is subjective.

The issue of consensus is discussed hereafter, but additional remarks regarding statistical analysis in the Delphi technique should first be made, namely that:

- the stability between rounds, in other words change in opinion, should be determined and mentioned (Greatorex \& Dexter, 2000:1016) as this is also an indication of consensus;

- data could be used to analyse further aspects, such as differences of opinion between groups in the sample, as was done by Almasio et al. (2005:386);

- to uphold anonymity, data can be analysed by independent partners (Almasio et al. 2005:383) and not by the research team;

- it might be valuable to report on each round separately, to enrich the description of the process and results; and

- in the research report readers should be informed on how to interpret the results.

\section{CONSENSUS}

Authors agree that the Delphi technique, alongside brainstorming and the nominal group technique, is a consensus method (Carrol, 2004:34; Avery et al. 2005:4). What distinguishes the Delphi technique from other consensus methods is that it is a group consensus method where anonymity is ensured and group members need not be physically assembled (De Villiers et al. 2005:1).

Powell (2003:377) refers to the achievement of consensus on a complex issue, characterised by uncertainty or lack of empirical evidence, as one of the main advamtages of the Delphi Technique. McKenna (1994: 
1223) and Beech (1999:283) also praise the ability of the Delphi technique to guide a group towards consensus and a final decision. However, the concept "consensus" appears to be subjective and its achievement a debatable matter. Williams and Webb (1994:183) report that consensus might be viewed as arbitrary if not explicitly described by researchers. Also, the danger exists that research results might not reflect true consensus, but a "watered down best opinion" (Powell, 2003:378, Williams \& Webb, 1994:183).

Another crucial aspect to take note of is that group consensus is not always achieved, and if it is achieved it should be the "most reliable consensus" (Linstone \& Turoff, 1975:10). This implies that the process through which consensus is achieved, as well as non-consensus if applicable, should be described in detail so that other researchers and evaluators may validate the quality of the work done.

Furthermore, the interpretation of the meaning of consensus in a particular study should be explained. According to Hasson et al. (2000:1011) there is no universally agreed-upon level of consensus and that consensus depends on the aim of the research, the sample size and resources. Powell (2003:379) explains that consensus might be expressed as percentage agreement or in terms such as "most participants agreed". The latter is criticised for being too vague. Avery et al. (2005:4), for instance, defined consensus as having been achieved if $90 \%$ or more of the panel members rated statements as "important" or "very important" after the second round.

Hasson et al. (2000:1011) as well as Greatorex and Dexter (2000:1022) warn that, in spite of the fact that anonymity is ensured to limit group members' influence on each other, the danger exists that consensus might be achieved because of panellists simply conforming to the collective group opinion (Halo effect). Researchers should thus not only take final responses, but also the stability of responses between rounds, into consideration when interpreting results (Powell, 2003:379). They should also describe how consensus was achieved, and measures should be implemented to limit the Halo effect, for example asking participants who deviated from their initial opinions to provide reasons for changing their opinions.
Consensus should not be seen as the "correct answer", and should be interpreted as the opinion of a specific group of experts on a given topic. It is recommended that the results of the Delphi technique are validated, for example, the results could be used as a guide to structure further discussion in workshops, focus group interviews, nominal groups and/or debates (French et al. 1996:597; Carrol, 2004:33; Hasson et al. 2000:1013).

\section{CONCLUSION}

The Delphi technique could be seen as having "added value". Its advantages include that it has the ability to elicit quantitative data similar to other survey research, but also to explore qualitative data such as attitudes and moral judgements (Beech, 1999:284). Furthermore, participating in this type of research might be a motivating and educational experience for participants. Participation might be viewed as an interesting exercise as it might stimulate new ideas (McKenna, 1994:1223). Additionally, the iterative nature of the research gives participants an indication of how their responses are utilised (Garavalia \& Gredler, 2004:375). This might lead to sharing of responsibility and a wider acceptance of results (Beech, 1999:287; McKenna, 1994:1223). For example, Cohen et al. (2004:1011) found Delphi research to be a useful way of involving nurses in research, as it created research awareness and communicated research as being rewarding. The Delphi technique thus has the ability to elicit follow-up research, guide further research and give direction in a discipline such as nursing (Cohen et al. 2004:1011; McKenna, 1994:1223).

In general, the Delphi technique is also viewed as costeffective (Beech, 1999:283; Williams \& Webb, 1994:180). It has the ability to generate large amounts of data (Beech, 1999:283), it is a flexible approach (Powell, 2003:377) and it enables data collection from participants who might be geographically separated (Evans et al. 2004:57). Although this type of research tend to be time-consuming, it might be completed in a relatively short time span (Armstrong et al. 2000:298; Evans et al. 2004:57; Powell, 2003:377; Williams \& Webb, 1994:182).

Looking at the limitations of the Delphi technique, as discussed throughout this article, one can understand why its respectability as a research approach is often 
questioned. Powell (2003:377) and Beech (1999:283) report criticism that indicate that the outcome of the Delphi technique could at best be viewed as subjective opinions regarding problems that can not otherwise be explored by means of more precise scientific instruments.

On the other hand, the advantages of the Delphi technique, as described, demonstrate the unmistakable value of this technique. It thus seems that the utilisation of this technique is advisable, but when utilising the Delphi technique, it should be used with caution, and great emphasis should be placed on measures to enhance validity and reliability, as discussed in this article. The following article is an example of the application of the Delphi technique.

\section{REFERENCES}

ALMASIO, PL; NIERO, M; ANGIOLI, D; ASCIONE, SG; MINOLI, G; OPRANDI, NC; PINZELLO, GB; VERME, G \& ANDRIULLI, A 2005: Expert's opinion on the role of liver biopsy in HCV infection: A Delphi survey by the Italian Association of Hospital Gastroenterologists (AIGO). Journal of Hepatology, 43(3):381-387.

ARMSTRONG, AE; PARSONS, S \& BARKER, PJ 2000: An inquiry into moral virtues, especially compassion, in psychiatric nurses: Findings from a Delphi study. Journal of Psychiatric and Mental Health Nursing, 7(4):297-306.

AVERY, AJ; SAVELYICH, BSP; SHEIKH, A; GANTRILL, J; MORRIS, CJ; FERNANDO, B; BAINBRIDGE, M; HORSFIELD, P \& TEASDALE, $S$ 2005: Identifying and establishing consensus on the most important safety features of GP computer systems: E-Delphi study. Informatics in Primary Care, 13(1):3-11.

BEECH, B 1999: Go the extra mile - use the Delphi Technique. Journal of Nursing Management, 7(5):281-288.

BRINK, HI 2002: Fundamentals of research methodology for health care professionals. Cape Town: Juta.

BURNS, N \& GROVE, SK 2005: The practice of nursing research. Conduct, critique and utilization. St. Louis: Elsevier.

CARROL, L 2004: Clinical skills for nurses in medical assessment units. Nursing Standard, 18(42):33-40.

COHEN, MZ; HARLE, M; WOLL, AM; DESPA, S \& MUNSELL, MF 2004: Delphi survey of nursing research priorities. Oncology Nursing Forum, 31(5):1011-1018.

COOK, C; BRISMEÉ, J-M; SIZER, PS 2005: Factors associated with physiotherapists' confidence during assessment of clinical cervical and lumbar spine instability. Physiotherapy Research International, 10(2):59-71.

DALKEY, NC \& ROURKE, DL 1971: Experimental assessment of
Delphi procedures with group value judgments. A report prepared for Advanced Research Projects Agency. Santa Monica: Rand. DESHPANDE, AM; SHIFFMAN, RN \& NADKARNI, PM 2005: Metadatadriven Delphi rating on the Internet. Computer Methods and Programs in Biomedicine, 77(1):49-56.

DE VILLIERS, MR; DE VILLIERS; PJT \& KENT, AP 2005: The Delph technique in health sciences education research. Medical Teacher, 27(7):639-643.

DU PLESSIS, E 2007: A strategy to promote nurses' health research contribution in South Africa. Potchefstroom: North West University. (Unpublished PhD thesis).

EVANS, C; ROGERS, S; McGRAW, C; BATTLE, G \& FURNISS, L 2004: Using consensus methods to establish multidisciplinary perspectives on research priorities for primary care. Primary Health care Research and Development, 5(1):52-59. FRENCH, P; ANDERSON, J; BURNARD, P; HOLMES, C; MASHABA, G; WONG, T \& BINGH-HUA, Z 1996: International comparison of baccalaureate nursing degrees: Collaboration in qualitative analysis. Journal of Advanced Nursing, 23(3):594-602.

FUSFELD, AR 1971: The Delphi technique: Survey and comment. Research program on the management of Science and Technology. Cambridge: Massachusetts Institute of Technology. GANSSLE, JG 2004: The middle way. Embedded Systems Programming, 17(11):54-56.

GARAVALIA, L \& GREDLER, M 2004: Teaching evaluation through modelling: Using the Delphi technique to assess problems in academic programs. American Journal of Evaluation, 25(3):375380.

GOODMAN, CM 1987: The Delphi technique: A critique. Journal of Advanced Nursing, 12(6):729-734.

GREATOREX, J \& DEXTER, T 2000: An accessible analytical approach for investigating what happens between the rounds of a Delphi study. Journal of Advanced Nursing, 32(4):1016-1024. HASSON, F; KEENEY, S \& McKENNA, H 2000: Research guidelines for the Delphi survey technique. Journal of Advanced Nursing, 32(4):1008-1015.

HELMER, O 1975: Foreword. (In: LINSTONE, HA \& TUROFF, M eds. 1975: The Delphi Method: Techniques and applications. Reading, Massachusetts: Addison-Wesley; pp xix-xx).

LINSTONE, HA \& TUROFF, M eds 1975: The Delphi Method: Techniques and applications. Reading, Massachusetts: Addison-Wesley. McKENNA, H 1994: The Delphi technique: A worthwhile research approach for nursing? Journal of Advanced Nursing, 19(6):1221-1225.

POWELL, C 2003: The Delphi technique: Myths and realities. Journal of Advanced Nursing, 41(4):376-382.

POWELL KENNEDY, H 2004: Enhancing Delphi research: Methods and results. Journal of Advanced Nursing, 45(5):504-511.

SACKMAN, H 1974: Delphi assessment: Expert opinion, forecast- 
ing, and group process. A report prepared for United States Air Force Project Rand. Santa Monica, CA: Rand.

WILLIAMS, PL \& WEBB, C 1994: The Delphi technique: A methodological discussion. Journal of Advanced Nursing, 19(1):180186. 